\title{
Central Representation of Postingestive Chemosensory Cues in Mice That Lack the Ability to Taste
}

\author{
Jennifer M. Stratford and Thomas E. Finger \\ Rocky Mountain Taste and Smell Center, Department of Cell and Developmental Biology, University of Colorado, Anschutz Medical Campus, Aurora, \\ Colorado 80045
}

The gustatory nerves of mice lacking $\mathrm{P} 2 \mathrm{X} 2$ and $\mathrm{P} 2 \mathrm{X} 3$ purinergic receptor subunits $(\mathrm{P} 2 \mathrm{X}$ - $d b l \mathrm{KO})$ are unresponsive to taste stimulation (Finger et al., 2005). Surprisingly, $P 2 X$-dblKO mice show residual behavioral responses to concentrated tastants, presumably via postingestive detection. Therefore, the current study tested whether postingestive signaling is functional in $P 2 X-d b l K O$ mice and if so, whether it activates the primary viscerosensory nucleus of the medulla, the nucleus of the solitary tract (nTS). Like WT animals, $P 2 X-$ dblKO mice learned to prefer a flavor paired with $150 \mathrm{~mm}$ monosodium glutamate (MSG) over a flavor paired with water. This preference shows that, even in the absence of taste sensory input, postingestive cues are detected and associated with a flavor in $P 2 X$ - $d b l K O$ mice. MSG-evoked neuronal activation in the nTS was measured by expression of the immediate early gene c-Fos [c-Fos-like immunoreactivity (Fos-LI)]. In anterior, gustatory nTS, $P 2 X$-dblKO animals, unlike WT animals, showed no taste quality-specific labeling of neurons. Furthermore, MSG-evoked Fos-LI was significantly less in $P 2 X-d b l K O$ mice compared with WT animals. In contrast, in more posterior, viscerosensory nTS, MSG-induced Fos-LI was similar in WT and $P 2 X-d b l K O$ mice. Together, these results suggest that $P 2 X-d b l K O$ mice can form preferences based on postingestive cues and that postingestive detection of MSG does not rely on the same purinergic signaling that is crucial for taste.

\section{Introduction}

Feeding is a complex behavior that relies on the coordination of multiple systems. Among these, the sense of taste (gustation) plays an important role in nutrient selection. The gustatory system is crucial for the detection and consumption of palatable, calorie-rich foods, as well as for detection and rejection of bittertasting substances. However, other sensory modalities also control intake of nutrients and avoidance of toxins. In fact, flavor is not only taste but an amalgamation including olfactory and trigeminal sensory inputs (Clark and Dodge, 1955). Thus, animals still perceive aspects of flavor even if taste is lost.

Furthermore, nutrient information about an ingested morsel involves not only taste, but also postingestive and postabsorptive systems (Berthoud, 2002). The path that nutrients traverse from the mouth to the lower gastrointestinal tract provides numerous opportunities for postoral feedback to drive or inhibit further intake (Zheng and Berthoud, 2008). Studies using esophageal

\footnotetext{
Received Jan. 24, 2011; revised May 2, 2011; accepted May 4, 2011.

Author contributions: J.M.S. and T.E.F. designed research; J.M.S. performed research; J.M.S. and T.E.F. analyzed data; J.M.S. and T.E.F. wrote the paper.

This work was supported by NIH Grants DC006070, DC00244, and P30 DC04657 and the Ajinomoto Amino Acid Research Program. We thank Debra Cockayne and Roche Palo Alto for providing WT and P2X2/P2X3 KO mice. Special thanks to Jennell Barrows, Marco Tatangleo, Jason Parnes, Nicole Shultz, Dianna Bartel, and Robert Hallock for immunohistochemistry technical support and assistance with c-Fos counting. We also thank Andrea Keglovits for her assistance with behavioral experiments. Finally, we thank the reviewers for their helpful comments and feedback.

Correspondence should be addressed to Dr. Jennifer Stratford, Rocky Mountain Taste and Smell Center, Department of Cell and Developmental Biology, University of Colorado Anschutz Medical Campus, $12801 \mathrm{E}$ 17th Avenue, P.0. Box 6511, Mail Stop 8108, Aurora, C0 80045-6511. E-mail: jennifer.stratford@ucdenver.edu.

DOI:10.1523/JNEUROSCI.0404-11.2011

Copyright $\odot 2011$ the authors $\quad 0270-6474 / 11 / 319101-10 \$ 15.00 / 0$
}

fistulae show that animals can use digestive cues to form a food preference (e.g., prefer a flavored solution when paired with an intragastric infusion of a nutrient) (Sclafani, 1988; Lucas and Sclafani, 1989; Uematsu et al., 2009, 2010). Conversely, mice learn to avoid a solution paired with a gastrointestinal irritant or bitter tastant (Kulkosky et al., 1981; Glendinning et al., 2008). Together, this suggests that the acceptance or rejection of food is based on postingestive signals as well as the detection of food molecules in the oral cavity.

Discerning the relative contributions of oral and postoral detection is difficult, as these two systems operate in tandem. Studies relying on esophageal fistulae to isolate digestive and ingestive processes are intrinsically invasive and also eliminate nongustatory oropharyngeal cues and processes. Knock-out mice lacking gustatory functions offer a means for isolating gustatory from nongustatory functions in an intact animal. The peripheral gustatory nerves of mice that lack purinergic $\mathrm{P} 2 \mathrm{X} 2$ and $\mathrm{P} 2 \mathrm{X} 3$ receptor subunits $(\mathrm{P} 2 \mathrm{X}-d b l \mathrm{KO})$ are unresponsive to taste stimulation, but are still responsive to thermal and tactile stimuli (Finger et al., 2005). The lack of gustatory neural responsiveness in $P 2 X-d b l K O$ mice is paralleled by a near total loss of preference for a majority of tastes (Finger et al., 2005; Eddy et al., 2009; Hallock et al., 2009). Despite the loss of taste, some elements of postingestive signaling in these mice appear intact (Hallock et al., 2009), i.e., $\mathrm{P} 2 \mathrm{X}$-dblKO mice use postingestive cues to avoid concentrated solutions of the bitter substance denatonium benzoate, suggesting that the elimination of $\mathrm{P} 2 \mathrm{X} 2$ and $\mathrm{P} 2 \mathrm{X} 3$ does not interfere with postingestive detection of toxic substances.

The current study tested whether $P 2 X$ - $d b l K O$ mice can form a preference for glutamate using only nongustatory signaling. 
Since detection of monosodium glutamate (MSG) in the digestive tract depends on an intact vagus nerve (Uematsu et al., 2010), we also examined nutrient-evoked brain activation in WT and $\mathrm{P} 2 \mathrm{X}$-dblKO mice, as measured by expression of the immediate early gene c-Fos [c-Fos-like immunoreactivity (Fos-LI)], in the nucleus of the solitary tract (nTS) - the primary sensory nucleus for both taste and viscerosensory gastrointestinal representation.

\section{Materials and Methods}

Animals

Adult $P 2 X 2 / P 2 X 3^{D b l-/-} K O(P 2 X-d b l K O, n=29)$ and WT control mice $\left(P 2 X 2 / P 2 X 3^{\text {Dbl+/+ }}, n=32\right)$ of both sexes ( 25 males, 36 females; age, $100-648 \mathrm{~d}$ ) were used. Despite the large age range in mice, there were no outliers in either behavioral performance or c-Fos-positive cell counts. Furthermore, there was no correlation between age and number of c-Fos-positive cells labeled $\left(r_{(41)}=0.0038, p=0.98\right)$. These mice were generated on a mixed C57BL/6 and 129Ola background, so genetic variability existed within both $P 2 X-d b l K O$ and WT populations. Finally, although $P 2 X-d b l K O$ mice lack the ability to taste and pup mortality is high, the growth rate and body weights of these animals resemble those of WT animals (our unpublished observation). The animals were housed in a vivarium with a $12 \mathrm{~h}$ light/dark cycle with lights on at 5:00 A.M. Food (Teklad Global Rodent Diet \#2918; Harlan) was available ad libitum throughout the course of the experiment. Water was also available ad libitum, except when noted otherwise.

All animal procedures were performed in accordance with NIH guidelines and were approved by the Institutional Animal Care and Use Committee at the University of Colorado Anschutz Medical Campus.

\section{Flavor preference conditioning and testing}

Preconditioning water training. WT and $P 2 X-d b l K O$ mice $(n=7$ each genotype) were placed on a water-restriction schedule in which animals had access to fluids only overnight for $18 \mathrm{~h}$ (4:00 P.M. to 10:00 A.M.). For $2 \mathrm{~d}$ before conditioning, animals were given $18 \mathrm{~h}$ access to one bottle of deionized water. An additional empty bottle was also placed on the cage so that the animals learned to investigate both bottles. At the end of each conditioning and testing day (see below), fluid intake was recorded.

Flavor conditioning. On conditioning days (D3-D10), animals were given $18 \mathrm{~h}$ access to two bottles. One bottle was empty and the other contained either Kool-Aid alone $(0.05 \%$ volume by weight; K alone) or a different flavor of Kool-Aid mixed with 150 mm MSG (K*+ MSG). The MSG was mixed with one Kool-Aid flavor (grape or cherry, $n=7$ each genotype) and the water was mixed with the other. Each solution (i.e., $\mathrm{K}$ alone or $\mathrm{K}^{\star}+\mathrm{MSG}$ ) was presented for $4 \mathrm{~d}$ and presentation alternated between days such that $\mathrm{K}$ alone was presented on D3, D5, D7, and D9; $\mathrm{K}^{\star}$ + MSG was presented on D4, D6, D8, and D10. Within each conditioning day, bottle placement (i.e., empty or Kool-Aid) was randomized.

Two-bottle preference testing. On D11 and D12, all animals were given two-bottle preference tests consisting of both Kool-Aid flavors alone; no MSG was added to either flavor (for timeline, see Fig. $1 B$ ). The preference for each Kool-Aid flavor was calculated [Kool-Aid flavor $(\mathrm{ml}) /$ total fluid intake $(\mathrm{ml})]$. Two approaches were used to ensure that one flavor of Kool-Aid was not inherently preferred over the other. First, before conditioning (i.e., before D1), a subset of animals ( $n=4$ of each genotype) was given two $18 \mathrm{~h}$ two-bottle Kool-Aid-preference tests (with no MSG in either). There was no significant difference between volumes consumed for the different flavors of Kool-Aid $\left(F_{(1,6)}=0.63, p=0.46\right)$; i.e., there was no innate preference for one Kool-Aid flavor over the other. Second, we determined whether animals could lose their preference for a previously preferred flavor by giving a second subset of animals ( $n=3$ of each genotype) additional MSG-free, two-bottle preference tests with the bottles containing Kool-Aid flavor only. These MSG-free two-bottle preference tests were repeated until all animals extinguished their preference for the conditioned flavor, further suggesting that one flavor was not naturally preferred over the other.

Flavor preference. In two separate groups, MSG was added to either grape or cherry Kool-Aid. The preference for the conditioned Kool-Aid flavor was similar between the two groups $\left(F_{(1,10)}=0.59, p=0.46\right)$. Therefore, these groups were combined into a single dataset.

\section{c-Fos presurgery water restriction and tastant stimulation}

To assess what brain areas were activated by MSG in WT and P2X-dblKO mice, we examined c-Fos activation in the nTS following consumption of various test solutions. Three days before tastant stimulation, mice were placed on $23 \mathrm{~h} / \mathrm{d}$ water restriction. During this time, animals were given $1 \mathrm{~h}$ access to water at the same time each day to train animals to consume fluids in a relatively short $(<1 \mathrm{~h})$ period of time. On stimulation day, animals were given either deionized water $(n=8 \mathrm{WT}$ and $n=7 \mathrm{P} 2 \mathrm{X}$ $d b l K O$ ) or one of two taste solutions in their home cage for $30 \mathrm{~min}$. At the end of $30 \mathrm{~min}$, fluid intake was recorded and animals were left undisturbed for $60 \mathrm{~min}$ before death.

One group received $150 \mathrm{~mm}$ MSG ( $n=6$ for each genotype). Because MSG has a sodium component in addition to its primary glutamate component, an additional set of animals were given $150 \mathrm{~mm} \mathrm{NaCl}(n=8$ WT and $n=6 P 2 X-d b l K O$ ), which contains the same amount of sodium as 150 mm MSG. To determine whether oral stimulation alone (regardless of tastant) induces c-Fos protein expression, six additional animals ( $n=3$ of each genotype) underwent the same water restriction as experimental animals, but were left undisturbed on stimulation day.

Fluid intake was consistent across all conditions (i.e., water, $\mathrm{NaCl}$, or MSG) and both genotypes (in milliliters per day: WT: water, $2.7 \pm 0.2$; $\mathrm{NaCl}, 3.2 \pm 0.1 ; \mathrm{MSG}, 3.1 \pm 0.2$; vs $P 2 X$-dblKO: water, $2.9 \pm 0.1 ; \mathrm{NaCl}$, $\left.3.2 \pm 0.2 ; \mathrm{MSG}, 3.0 \pm 0.2 ; F_{(1,2)}=0.88, p=0.42\right)$, indicating that any differences in c-Fos expression was not attributable to differences in the amount of tastant consumed.

\section{c-Fos immunohistochemistry}

Sixty minutes following the end of taste stimulation, animals were deeply anesthetized with sodium pentobarbital (50 mg/kg i.p., $n=19$; Ovation Pharmaceuticals) or chloral hydrate ( $400 \mathrm{mg} / \mathrm{kg}$ i.p., $n=22$; SigmaAldrich) and perfused transcardially first with $0.9 \%$ saline and then with $4 \%$ paraformaldehyde in $0.1 \mathrm{~m}$ phosphate buffer. Following perfusion, the brain was removed and postfixed in $4 \%$ paraformaldehyde with $20 \%$ sucrose overnight at $4^{\circ} \mathrm{C}$. Approximately $18 \mathrm{~h}$ postfixation, the olfactory bulbs and brainstem were isolated, embedded in optimal cutting temperature compound (Fisher Scientific), and frozen rapidly on dry ice. Coronal sections $(40 \mu \mathrm{M})$ were cut on a cryostat and divided into a series of three adjacent sets. Sections were either reacted immediately or placed in cryoprotectant and stored at $-20^{\circ} \mathrm{C}$ (Watson et al., 1986) for later processing. Sections stored in cryoprotectant were thoroughly rinsed in $0.1 \mathrm{M}$ PBS before staining.

All steps were conducted at room temperature unless otherwise indicated. Sections were first washed in $0.1 \mathrm{~m}$ PBS with $0.4 \%$ Triton X-100 (PBST). Endogenous peroxidase activity in sections was quenched using $1 \%$ hydrogen peroxide. Following an additional three washes in $0.4 \%$ PBST, sections were blocked in $1 \%$ normal goat serum for $1 \mathrm{~h}$ and then incubated in rabbit anti-Fos (for details, see c-Fos antisera below) at $4^{\circ} \mathrm{C}$ for $48-72 \mathrm{~h}$.

Following incubation, the anti-Fos antibody was detected with a biotinylated goat anti-rabbit antibody (Vector BA-1000; lots \#Q0923, U0702, and V0111; dilution, 1:667), followed by avidin-biotin reagent (Vector Elite kit, SK-6100; Vector Laboratories) for $1 \mathrm{~h}$ each. Then sections were incubated in a diaminobenzidine $(0.05 \%)$ substrate with nickel intensification ( $0.02 \%$, Vector SK-4100) and monitored periodically under a microscope until a dark nuclear stain was observed. For a subset of cases $(n=3)$, omission of rabbit anti-c-Fos antibody resulted in no labeled cells (data not shown). Sections were washed with $0.02 \%$ PBST between each reaction. Following an additional three washes in $0.02 \%$ PBST, sections were mounted and dried on Fisher Superfrost Plus slides, dehydrated in 95 and 100\% alcohol washes, dipped in xylene and then coverslipped with Permount. Selected sections were counterstained with neutral red before coverslipping.

\section{c-Fos antisera}

Sections were processed for Fos-LI using two different rabbit polyclonal anti-c-Fos antibodies. One (catalog \#SC-52, lot \#H0806, working dilution 1:10,000, $n=6$; Santa Cruz Biotechnology) was prepared against a peptide mapping to residues 3-16 of the c-Fos p62 protein of human origin. The antiserum stains a single band at $62 \mathrm{kDa}$ on Western blot 


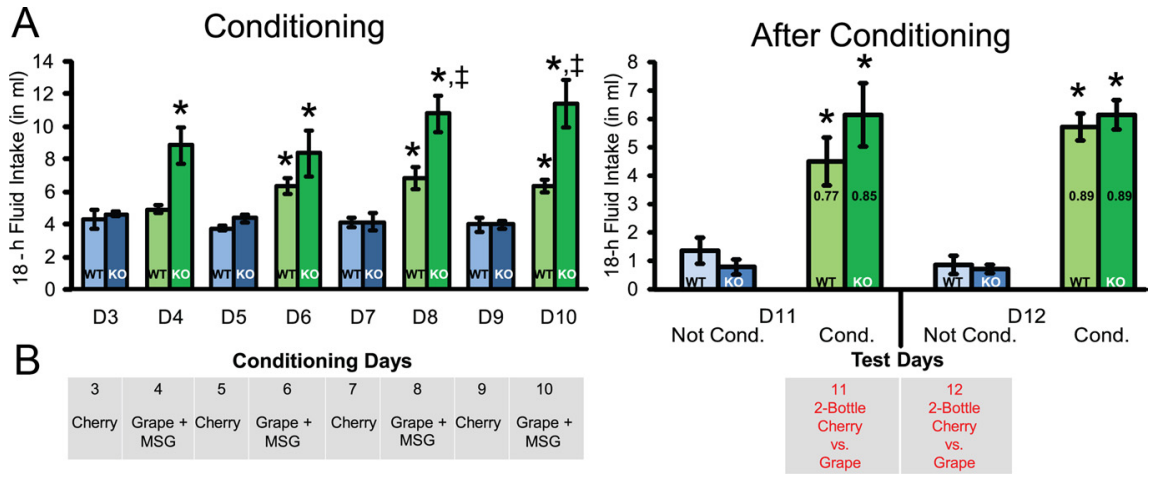

Figure 1. $\quad P 2 X-d b / K O$ mice, like WT mice, develop conditioned flavor preferencesto MSG.A, Bar graphs showing daily fluid intake during conditioning trials (left) and after conditioning (right). Darker colors show intake for $P 2 X$-dbIKO, lighter colors for WT. Green bars indicate the behavior related to the conditioned stimulus, blue bars for the flavor presented in water. During conditioning, both WT and P2X-dbIKO animals consumed more of the Kool-Aid flavor mixed with MSG (K* + MSG) than Kool-Aid alone (K alone) across eight training days (D3-D10), although P2X-db/KO animals consumed significantly more $K^{*}+$ MSG than did WT animals - even on the first $K^{*}+$ MSG training day. After conditioning (right), both WT and $P 2 X$-dbIKO animals preferred the Kool-Aid flavor that was previously mixed with MSG (Cond.) over the Kool-Aid flavorthat was presented in plain water (NotCond.). ${ }^{*}, K^{*}+$ MSG intake significantly greater than Kalone intake; F, P2X-dbIKO $K^{*}+$ MSG intake significantly greater than WT $K^{*}+$ MSG intake, $p<0.05$. B. Example timeline of conditioning and postconditioning testing for one MSG-flavor pairing (MSG in grape) that corresponds to the conditioning and test day data presented in $\boldsymbol{A}$. This MSG-flavor pairing was reversed (MSG in cherry) for half of the animals of each genotype.

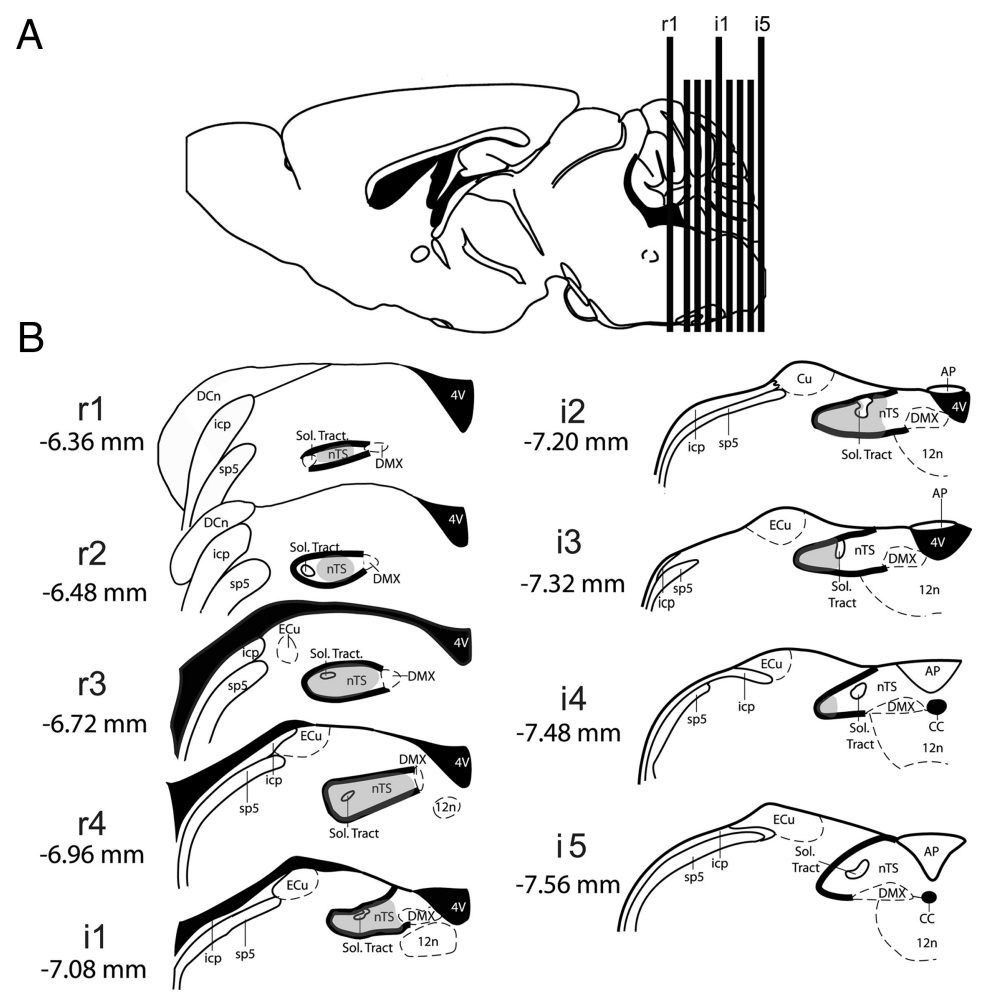

Figure 2. Standard counting planes include both gustatory and nongustatory portions of the nTS. A, Sagittal schematic of nTS levels in relation to the rest of the brain. $\boldsymbol{B}$, Nine rostrocaudal $n T S$ levels designated as anterior/rostral ( $r 1-\mathrm{r} 4$ ) and intermediate (i1-i5). Coordinates from bregma are listed for each nTS level. The boundaries of the nTS in each level are indicated with bold lines. The gray shading indicates areas of taste and orosensory presence based on previous studies on central projections of the chorda tympani, glossopharyngeal, greater superficial petrosal nerves, the trigeminal nerve, and electrophysiological recordings (Whitehead and Frank, 1983; Travers, 1993; Travers and Norgren, 1995; Hallock and Di Lorenzo, 2006; McCaughey, 2007; Whitehead and Finger, 2008; Corson et al., 2010). AP, Area postrema; CC, central canal; $\mathrm{Cu}$, cuneate nucleus; $\mathrm{DCn}$, dorsal cochlear nucleus; $\mathrm{ECu}$, external cuneate nucleus; icp, inferior peduncle; $\mathrm{nTS}$, nucleus of the solitary tract; sp5, spinal trigeminal tract; Sol. Tract, solitary tract; 4 V, fourth ventricle; DMX, dorsal motor nucleus of the vagus; 12n, hypoglossal nucleus. Images modified from Paxinos and Franklin (2001).

using rat brain tissue (manufacturer's technical information). The other c-Fos antibody (Ab-5, catalog \#PC38, lots \#D00029671, D00058535, D00085644; working dilution 1:10,000, $n=35$ Calbiochem) was prepared against a peptide mapping at residues $4-17$ of the human c-Fos protein. This antiserum stains a single band at $\sim 50-55 \mathrm{kDa}$ as observed by Western blot analysis of fibroblastlike BHK 21 C13 cells (Archer et al., 1999). Both antibodies had virtually identical patterns of staining and produced similar quantitative results. A three-way ANOVA of the total number of cells for each genotype showed no significant difference between antisera $\left(F_{(1,8)}=0.34, p=0.58\right)$. Thus, c-Fos cell counts for each antibody for each genotype were included together.

\section{Microscopic analysis}

Reference images of brainstem sections were photographed at $10 \times$ magnification using $Q$ Capture software (QImaging) with a monochrome Q-imaging camera on an Olympus BX41TF microscope. Brightness and contrast of photographs were optimized using Adobe Photoshop 9.0 using the levels and sharpen image tools. However, these images were then printed out and used only for reference, as all actual cell counting was done using the original coverslipped slides viewed on an Olympus BH-2 microscope. Cells were counted if the cell nucleus was elliptical and significantly darker than the background, as judged by the observer. Cases were counted only when substantial Fos-LI was observed in the olfactory bulb, as c-Fos expression is robust in the olfactory bulb in all animals (Guthrie et al., 1993). Three double-blind observers counted the labeled cells in the nTS. To establish inter-rater reliability, all observers counted a subset of seven randomly selected sections. The intraclass correlation coefficient between raters was calculated in SPSS 16.0 (SPSS) to establish the correlation between the three raters' counts. This analysis showed an intraclass correlation of 0.95 , indicating that the cell counts of all three raters were highly correlated. Thus, cell counts from all three observers were included together in the final dataset.

\section{Representative levels of the nucleus of the} solitary tract

To fully examine c-Fos expression in the nTS, we used a counting approach adapted from King et al. (1999) and Chan et al. (2004). The number of c-Fos-positive cells was quantified in six subfields of the nTS in each coronal plane (medial-mid-lateral each and dorsal-ventral tiers) and nine rostrocaudal levels.

The boundaries of the nTS were outlined in unstained tissue for the majority of cases. However, tissue from adjacent sets was stained with neutral red (1\%; Mallinckrodt Baker) for a subset of cases $(n=3)$ to confirm nTS boundaries and ensure consistent delineation of the nTS.

\section{Statistics}

Data are presented as group means \pm SE. Data were analyzed using appropriate one-, two-, or three-way ANOVAs (Statistica; StatSoft), with repeated measures for within-subjects effects where applicable. Tukey's honest significant difference tests were used to assess statistically significant $(p<0.05)$ main effects or interactions.

Cell counts. To test whether cells had similar sizes in the WT and $P 2 X-d b l K O$ mice, the nuclear diameter of c-Fos-positive cells was mea- 
A

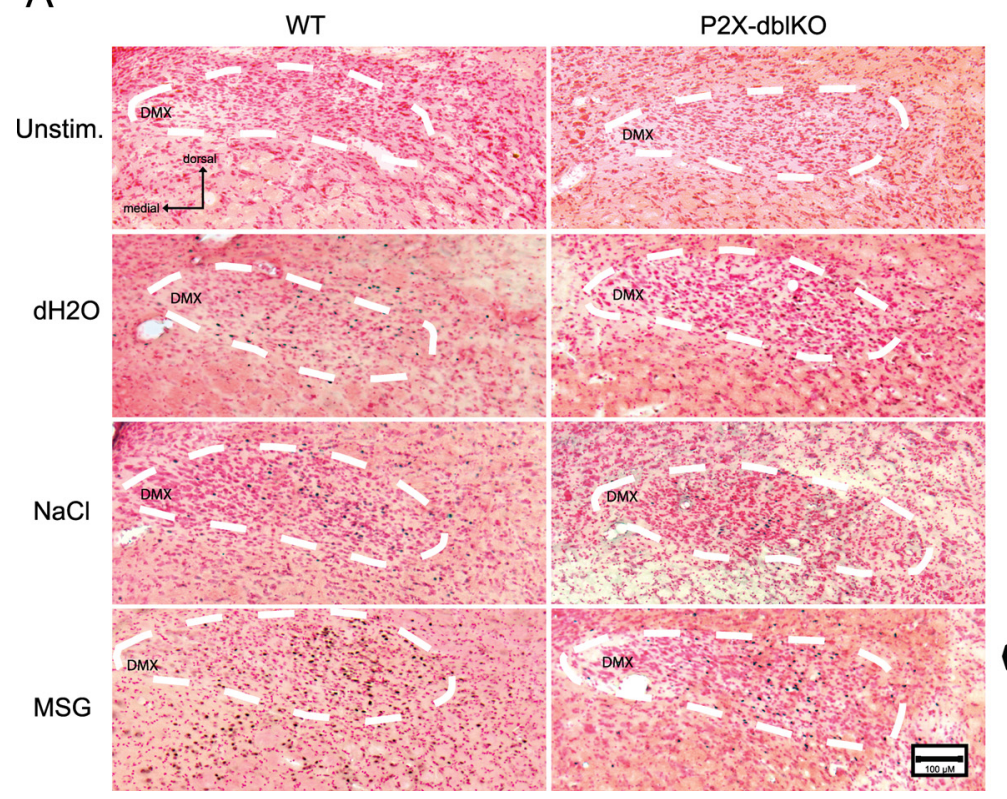

B
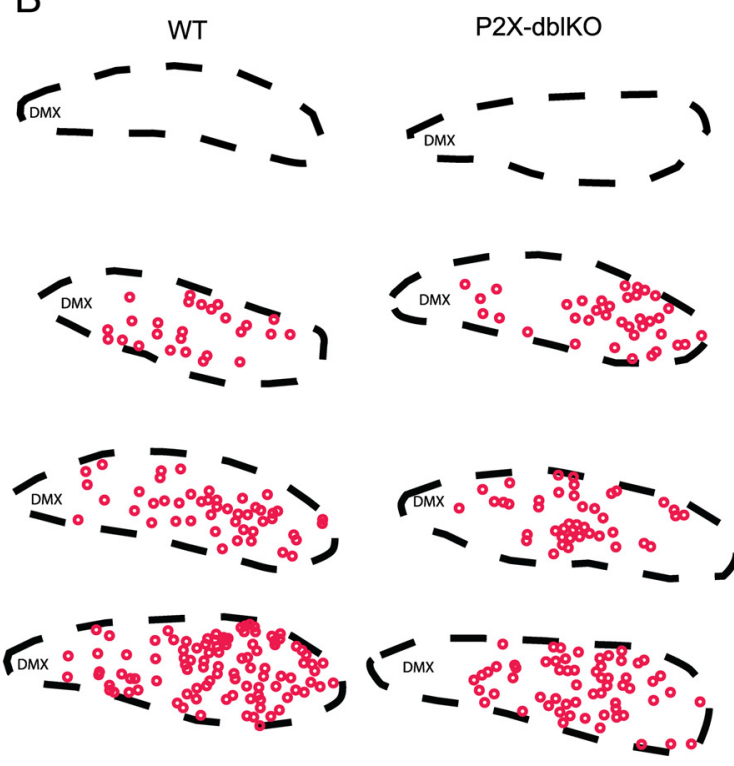

Figure 3. Tastant-evoked Fos-LI in the nTS. $\boldsymbol{A}, \boldsymbol{B}$, Photomicrographs $(\boldsymbol{A})$ and chartings $(\boldsymbol{B})$ of Fos-LI cells in the $n T S$ in response to no stimulation (Unstim.; top row), stimulation by water (second row), NaCl (third row), or MSG (bottom row). $A$, Micrographs counterstained with neutral red in the r4 $\mathrm{nTS}$ level of WT (left) and P2X-dbIKO (right). $B$, Outlines of the nTS and chartings showing c-Fos-positive cells from $A$. DMX, Dorsal motor nucleus of the vagus; dH20, deionized water;

sured for a subset of cases ( $n=6$, three of each genotype) using the measure function in Image ( $\mathrm{NIH}$ ). First, nuclear size was measured for 10 cells in each of three nTS levels ( $\mathrm{r} 3, \mathrm{i} 1$, and i5; 30 counts total) for each animal. Then, these counts were averaged across the three nTS levels into 10 values for each animal. Since the size of the nucleus was similar between genotypes $\left(7.6 \pm 0.9\right.$ and $7.4 \pm 0.9$; one-way ANOVA; $F_{(1,18)}=$ $0.02, p=0.89)$, no correction factor was necessary to compare counts from the different conditions or genotypes.

Calculation of tastant-specific Fos-LI. Adopting methodology similar to that used by Schwarz et al. (2010), we quantified the degree of c-Fos activation that is specific to each tastant as opposed to c-Fos induced merely by drinking. For each subfield at each nTS level, the average number of c-Fos-positive cells induced by drinking water alone was subtracted from the number induced by consumption of a tastant. In this way, we obtained values for tastant ( $\mathrm{NaCl}$ or MSG)-specific Fos-LI. Furthermore, by subtracting the values for $\mathrm{NaCl}$ from the values from MSG, we obtained a measure of glutamate-specific induction of c-Fos, i.e., the difference between the number of cells activated by MSG and the number induced only by the equimolar sodium component. This enabled us to generate heat maps, similar to fMRI activity maps showing the relative level of activation (number of raw or stimulated c-Fos-positive cells) for each subfield of the nTS. This method of visualizing cell activation in the nTS reveals patterns not evident in previous studies (Harrer and Travers, 1996; King et al., 1999; Travers et al., 1999; Travers, 2002; Chan et al., 2004; Travers and Travers, 2007).

\section{Results}

\section{Flavor preference}

Before conditioning, neither WT nor $\mathrm{P} 2 \mathrm{X}$-dblKO animals showed a preference for one flavor of Kool-Aid over the other $\left(F_{(1,6)}=0.63, p=0.46\right)$ (data not shown). Moreover, intake of solutions lacking MSG was similar for WT and KO lines and did not change throughout the course of testing $\left(F_{(3,18)}=2.33, p=0.11\right)$.

Both WT and P2X-dblKO mice drank significantly more of the MSG-containing solution than of the $\mathrm{K}$ alone solution $\left(F_{(1,24)}=46.6, p<0.05\right)$. Strikingly, $P 2 X-d b l K O$ animals consumed significantly more $\mathrm{K}^{\star}+$ MSG than $\mathrm{K}$ alone even during their first exposure to $\mathrm{K}^{\star}+\operatorname{MSG}\left(F_{(1,12)}=12.0, p<0.05\right)$ (Fig. $1 A$, left). Furthermore, $P 2 X-d b l K O$ mice continued to increase their intake significantly of $\mathrm{K}^{*}+$ MSG on subsequent days; $P 2 X$ dblKO mice consumed $1.25 \times$ more $\mathrm{K}^{*}+\mathrm{MSG}$ on D10 (fourth trial with MSG) than they did on the first two exposures to MSG (post hoc $p<0.05$ ). In contrast, WT mice drank significantly less $\mathrm{K}^{\star}+$ MSG than did P2X-dblKO mice on D6 and D8 $\left(F_{(1,24)}=\right.$ 9.76, $p<0.05)$, although by $\mathrm{D} 10$ this amount by was still $1.6 \times$ more than that for $\mathrm{K}$ alone $(p<0.05)$.

Following conditioning, both genotypes learned to associate the paired Kool-Aid flavor with MSG intake, with average preference scores of $0.81 \pm 0.05$ and $0.89 \pm 0.02$ for the two test days $\left(\mathrm{D} 11\right.$ and D12, respectively; $F_{(1,24)}=8.37, p<0.05$; MSG-paired flavor significantly different from flavor alone for both genotypes) (Fig. $1 A$, right). Finally, in both WT and $P 2 X-d b l K O$ mice, this conditioned preference was extinguished by $4 \mathrm{~d}$ of postconditioning exposure to Kool-Aid lacking MSG (i.e., D16; $F_{(5,40)}=$ $2.91, p<0.05$; post hoc $p<0.05)$, with an average preference of $0.49 \pm 0.05$ and $0.51 \pm 0.05$ (data not shown, $p=0.94$ ) for each Kool-Aid flavor at the end of the extinguishing period. Together, these results suggest that postingestive signaling is intact in the $\mathrm{KO}$ mice and, even in the absence of gustatory sensory information, enables these animals to form an association for ingested chemicals.

\section{c-Fos}

The overall organization and morphology of the nTS appeared similar in the WT and P2X-dblKO mice. Accordingly, we counted c-Fos-positive cells in a standard series of sections from the two genotypes. The rostrocaudal levels are designated as rostral ( $\mathrm{r} 1-$ r4) and intermediate (i1-i5); situated respectively at -6.36 , $-6.48,-6.72,-6.96,-7.08,-7.20,-7.32,-7.48$, and -7.56 from bregma (Fig. 2). In accordance with previous studies on central projections of the chorda tympani, glossophyaryngeal, and greater superficial petrosal nerves, the trigeminal nerve, and electrophysiological recordings (Whitehead and Frank, 1983; Norgren and Smith, 1988; Travers, 1993; Travers and Norgren, 1995; Hallock and Di Lorenzo, 2006; McCaughey, 2007; White- 


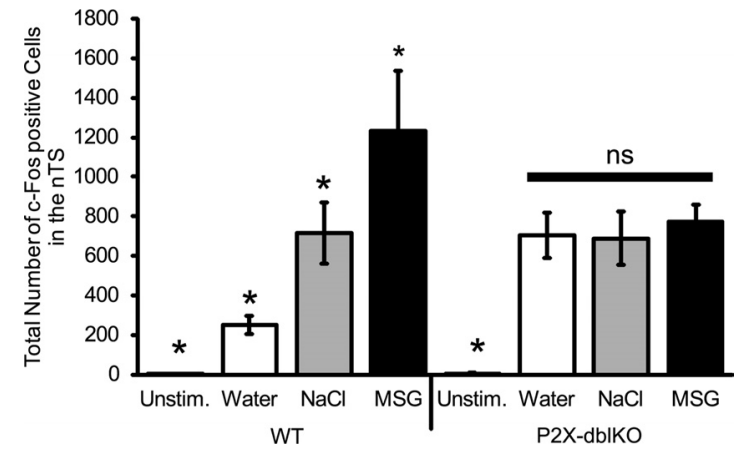

Figure 4. Total number of c-Fos-positive cells in the nTS of WT (left) and P2X-dbIKO (right) mice across stimuli. Unstimulated animals had few c-Fos-positive cells in the nTS of either genotype. However, taste stimulation produced Fos-LI in a graded manner with water $<$ $\mathrm{NaCl}<$ MSG in the nTS of WT animals. In contrast, Fos-Ll across all stimuli (water, NaCl, and MSG) was similar in the nTS of P2X-dbIKO animals. ns, Not significantly different; ${ }^{*}$, each stimulus is significantly different from all other taste stimuli and water, $p<0.05$.

head and Finger, 2008; Corson et al., 2010), taste and orosensory information impacts on anterolateral parts of the nTS including (r1-r4) and lateral portions of i1, i2, and i3; whereas visceral representation predominates in posteromedial areas of nTS (i4 and i5) (Norgren and Smith, 1988; Berthoud, 2002) and the medial part of i2 and i3 (Fig. $2 B$, gray shading).

In all cases of both WT and $P 2 X$-dblKO lines, oral stimulation by water or a tastant produced more Fos-LI than in unstimulated mice of either genotype. Few c-Fos-positive cells appeared in the nTS of animals that received no oral stimulation $(2.2 \pm 1.0$ counted cells per case for WT; $6.7 \pm 3.8$ for P2X-dblKO) (Fig. 3). Moreover, the number of c-Fos-positive cells in unstimulated cases was significantly less than Fos-LI in response to any oral stimulation-water, $\mathrm{NaCl}$, or MSG (range of 251.4-1233.5 for the three stimuli in WT; 689.7-774.0 for P2X-dblKO; all $p<$ $0.05)$. The amount of Fos-LI between unstimulated WT and $P 2 X-d b l K O$ mice was not significantly different $\left(F_{(1,4)}=1.31\right.$, $p=0.32$ ).

\section{Stimulated Fos-LI}

The magnitude and pattern of Fos-LI in response to oral stimulation (i.e., water, $\mathrm{NaCl}$, or MSG) was different between WT and $P 2 X$-dblKO mice (Figs. 3 and 4). Although in both genotypes, all stimuli evoked more Fos-LI than the nonstimulated condition, the relative activation differed by taste quality for WT but not for $P 2 X$-dblKO mice, i.e., $P 2 X$ - $d b l K O$ mice showed no difference in the amount of c-Fos activation for water, $\mathrm{NaCl}$, or MSG.

In WT animals, the number of c-Fos-positive cells in response to water, $\mathrm{NaCl}$, and MSG was graded with MSG stimulation > $\mathrm{NaCl}$ stimulation $>$ water stimulation $\left(F_{(3,17)}=4.76, p<0.05\right.$; post hoc, $p<0.05)$. Strikingly, the number of c-Fos-positive cells in response to water was significantly greater $(p<0.05)$ in $P 2 X-$ dblKO mice than in WT mice (WT: $251.4 \pm 45.1 ; P 2 X-d b l K O$ : $703.1 \pm 115.2)$. However, this number was similar to that observed across all oral stimuli in $P 2 X-d b l K O$ mice $\left(F_{(2,16)}=0.15\right.$, $p=0.86$ ) (Figs. 3 and 4 ). The number of c-Fos-positive cells evoked by each stimulus in $P 2 X-d b l K O$ mice was approximately half the number activated by MSG and approximately equal to the number following exposure to $\mathrm{NaCl}$ in the WT animals ( $p=$ $0.8,0.9$, and 0.95$)$. The equivalent number of c-Fos-positive cells in response to oral stimuli parallels the inability of $P 2 X-d b l K O$ mice to discriminate by taste between water, $\mathrm{NaCl}$, and MSG (Finger et al., 2005).
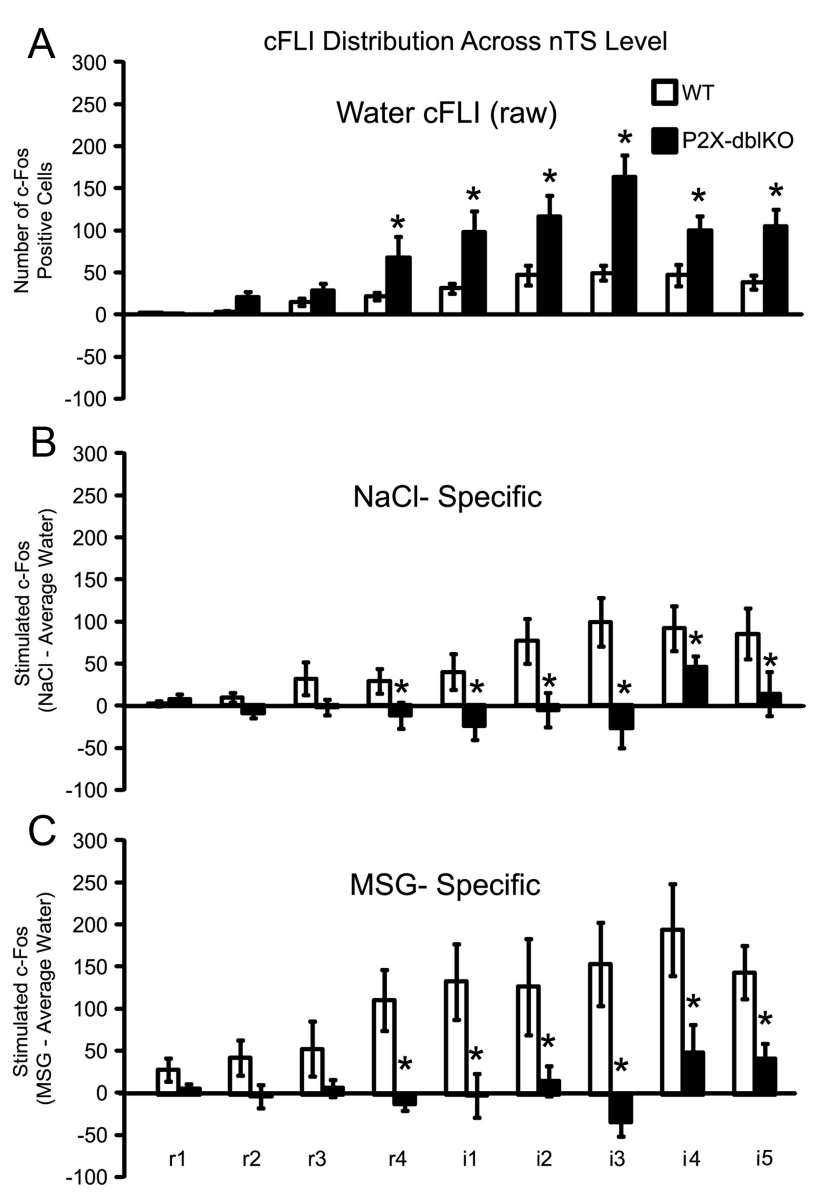

Figure 5. Unlike WT animals, P2X-db/KO mice show little tastant-specific activation in the gustatory $n T S$. Bar graphs showing the number of tastant-specific Fos-LI (tastant - average water raw counts) at each level of the nTS in WT and P2X-db/KO animals. $\boldsymbol{A}-\boldsymbol{C}$, Although water $(\boldsymbol{A})$ produced significantly more Fos-LI in the nTS of P2X-dbIKO mice than in WT mice, both MSG and NaCl stimulation produced significantly less NaCl-specific ( $\boldsymbol{B}$ ) and MSG-specific (C) Fos-LI. This is attributable largely to a significant increase in water-induced label and concomitant decrease in tastant-specific Fos-LI at $\mathrm{r} 4, \mathrm{i} 1, \mathrm{i} 2, \mathrm{i} 3, \mathrm{i} 4$, and i5. ${ }^{*}$, $\mathrm{KO}$ significantly different from WT, $p<0.05$.

\section{Tastant-specific Fos-LI}

Tastant-specific activation (number of c-Fos-positive cells for the tastant minus the average number of c-Fos-positive cells for water) differed significantly between genotypes. Overall, both $\mathrm{NaCl}$-specific and MSG-specific activation was significantly less in P2X-dblKO animals when compared with WT mice (for $\mathrm{NaCl}$ : WT: $983 \pm 300, P 2 X-d b l K O: 72.6 \pm 83.7, F_{(1,12)}=4.90, p<0.05$; for MSG: WT: $463.1 \pm 155.4, P 2 X-d b l K O:-13.5 \pm 136.1$, $F_{(1,10)}=8.55, p<0.05$ ) (Fig. $5 B, C$ ). The low values for $\mathrm{NaCl}$ and MSG-specific Fos-LI in the P2X-dblKO line reflects the similar levels of activation by water, $\mathrm{NaCl}$, and MSG (Fig. 4). In contrast, in WT mice, MSG evoked four times the number of c-Fos-positive cells and $\mathrm{NaCl}$ evoked nearly three times the number of c-Fos-positive cells than did water.

For a more detailed analysis of the regional distribution of tastant-specific Fos-LI, we compared taste-evoked activation in each subregion and level of the nTS (for details, see Materials and Methods and Fig. 2) to water-induced activation (MSG vs water, $\mathrm{NaCl}$ vs water) (Table 1). The greatest difference in Fos-LI between WT and $\mathrm{P} 2 \mathrm{X}$-dblKO mice was a loss of tastant-evoked activity in anterolateral nTS - especially in dorsal subregions, in gustatory-responsive parts of the nTS (Fig. 2, gray shading). In WT but not P2X-dblKO mice, substantial NaCl- and MSGspecific Fos-LI was evident throughout the rostrocaudal extent of 
Table 1. Raw counts of the number of c-Fos positive cells in response to water, NaCl and MSG stimulation in the nTS of WT and P2X-db/KO animals

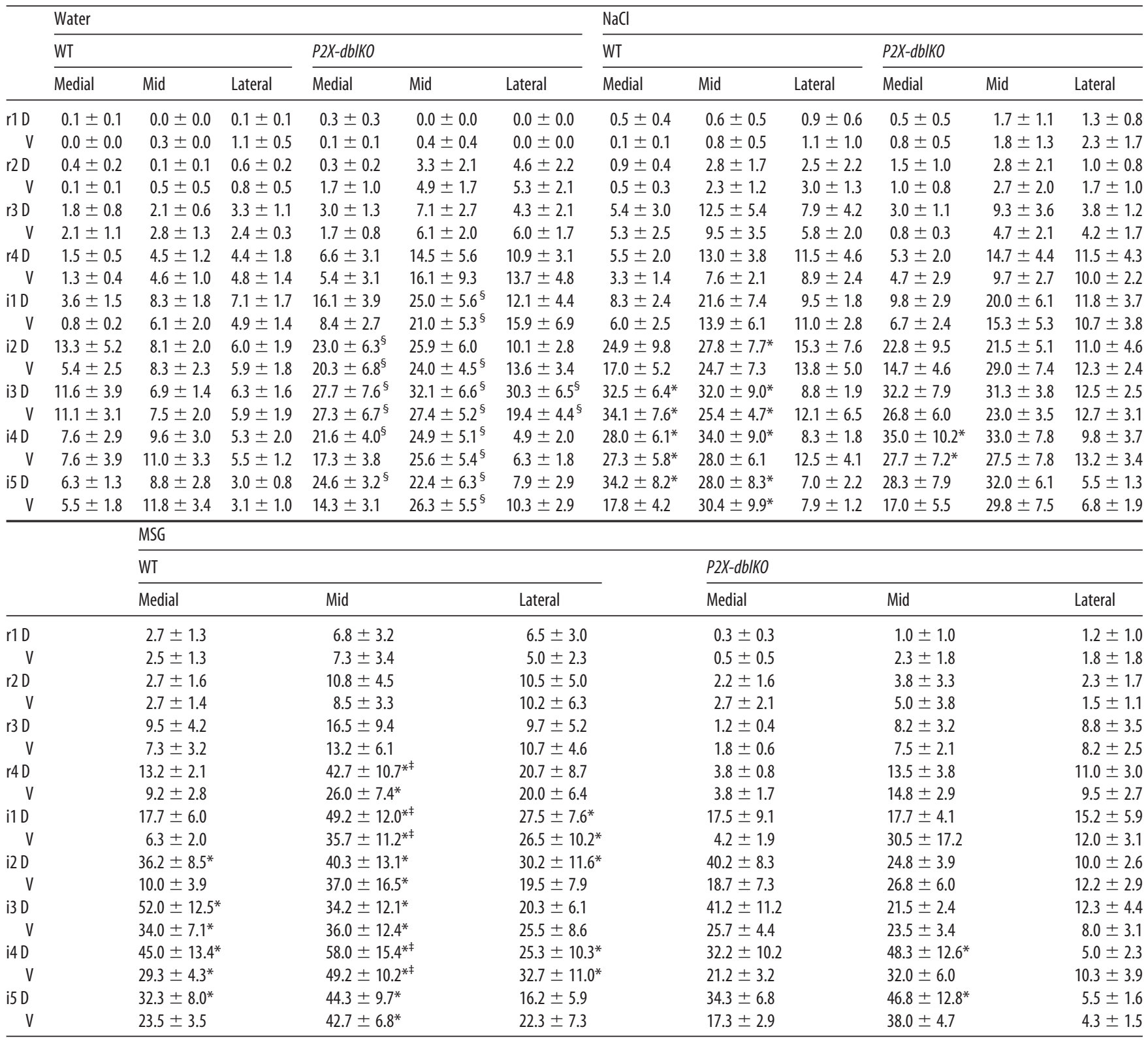

$\mathrm{D}$, Dorsal; $\mathrm{V}$, ventral. ${ }^{*}$, Significantly different from water-evoked Fos-LI within each genotype; ${ }^{\ddagger}, \mathrm{MSG}$-evoked c-Fos expression significantly different from NaCl-evoked c-Fos expression; ${ }^{5}$, WT significantly different from $P 2 X-d b / K O$.

the nTS, including both gustatory and general visceral regions. In particular, both NaCl- and MSG-specific Fos-LI at r4, i1, i2, i3, i4, and i5 were significantly less for $P 2 X-d b l K O$ than WT mice $\left(\mathrm{NaCl}: F_{(8,96)}=3.49, p<0.05\right.$; MSG: $F_{(8,80)}=3.48, p<0.05$; post hoc all p's $<0.05$ ) (Fig. $5 B, C$ ).

Furthermore, the topography of Fos-LI within each nTS subfield (dorsal-ventral, medial-lateral) was different between tastants as well as genotypes. In WT animals (Fig. 6C), MSG-specific Fos-LI in the anterior (gustatory) nTS was greatest in the $\mathrm{r} 4$ and $\mathrm{i} 1$ dorsal mid subfields $\left(F_{(8,760)}=1.51, p<0.05\right.$; post hoc comparisons all $p s<0.05)$ - areas that receive primary gustatory afferent input from the chorda tympani and glossopharyngeal nerves (Whitehead and Frank, 1983). However, the area of highest activation shifted to include medial subfields at more caudal, nongustatory nTS levels (i3 and i4; post hoc ps < 0.05) (Fig. 6C, left).

In contrast, in the gustatory nTS of WT mice, $\mathrm{NaCl}$-specific Fos-LI was approximately half that following MSG stimulation. Moreover, the pattern of NaCl-specific Fos-LI was different from that observed in response to MSG stimulation, with the greatest area of $\mathrm{NaCl}$-specific activation occurring more posteriorly (e.g., i3) and medially $\left(F_{(8,760)}=1.51, p<0.05\right.$; post hoc comparisons, $p<0.05$ ) (Fig. 6, $B, C$, left; Table 1) than for MSG.

At rostral levels of the nTS of $P 2 X-d b l K O$ mice, both NaClspecific and MSG-specific Fos-LI was comparatively even across subfields. However, in the visceral nTS, there was significant activation in the dorsal medial and dorsal mid subfields $(\mathrm{NaCl}$ : $F_{(40,440)}=0.81, p<0.05$; MSG: $F_{(40,440)}=1.44, p<0.05$; post hoc all $p s<0.05$ ) (Fig. $6 B, C$, right; Table 1 ). These patterns were even more apparent when comparing glutamate-specific (MSG$\mathrm{NaCl}$ ) induction of Fos-LI in WT and $\mathrm{P} 2 \mathrm{X}$ - $d b l \mathrm{KO}$ mice (Fig. $6 \mathrm{D}$ ). Finally, tastant-specific spatial patterns of activation in the more caudal nTS were similar between WT and $P 2 X$-dblKO mice, although the amount of activation in $\mathrm{KO}$ mice was less than that of WT mice, suggesting that $\mathrm{P} 2 \mathrm{X} 2 / 3$ receptors may be involved in, but are not necessary for, postingestive detection of nutrients. These results are summarized in Table 1.

In summary, in $\mathrm{P} 2 \mathrm{X}$ - $d b l \mathrm{KO}$ mice lacking taste abilities, c-Fos expression in the gustatory nTS is not tastant-specific, i.e., all 
A

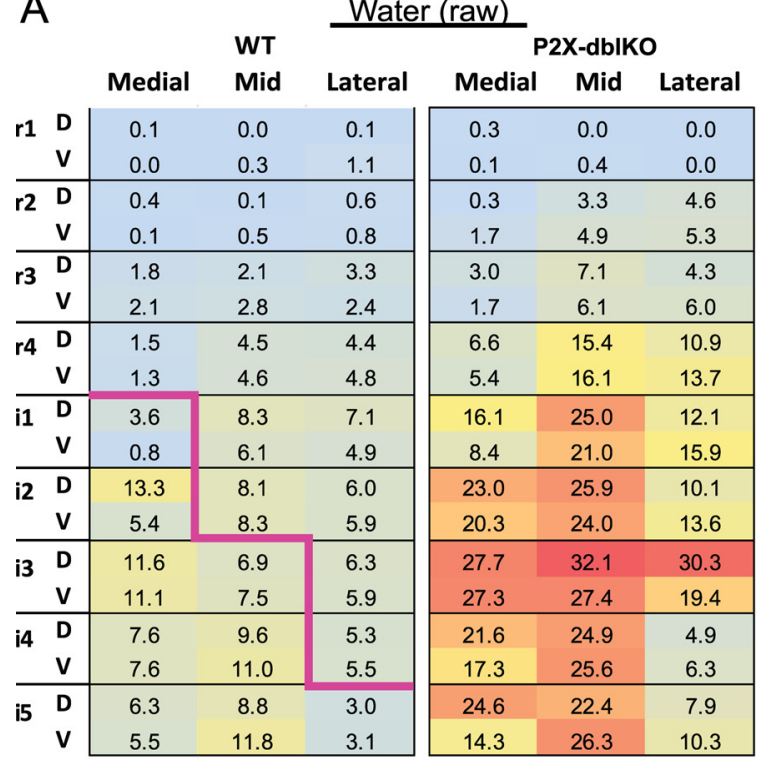

C

\begin{tabular}{|c|c|c|c|c|c|c|}
\hline & \\
\hline & \multicolumn{3}{|c|}{ WT } & \multicolumn{3}{|c|}{ P2X-dbIKO } \\
\hline & Medial & Mid & Lateral & Medial & Mid & Lateral \\
\hline \multirow[t]{2}{*}{ r1 } & 2.5 & 6.8 & 6.3 & 0.0 & 1.0 & 1.2 \\
\hline & 2.3 & 6.7 & 4.8 & 0.4 & 1.9 & 1.8 \\
\hline \multirow[t]{2}{*}{2} & 0.5 & 10.5 & 10.0 & 1.9 & 0.5 & -2.2 \\
\hline & 1.5 & 7.8 & 9.5 & 1.0 & 0.1 & -3.8 \\
\hline \multirow[t]{2}{*}{ r3 } & 7.0 & 14.3 & 5.8 & -1.8 & 1.0 & 4.5 \\
\hline & 4.2 & 9.5 & 9.0 & 0.1 & 1.4 & 2.2 \\
\hline \multirow{2}{*}{ r4 } & 10.3 & $36.2 *$ & 14.2 & -2.7 & -1.9 & 0.1 \\
\hline & 6.8 & $18.2 *$ & 14.0 & -1.6 & -1.3 & -4.2 \\
\hline \multirow[t]{2}{*}{ i1 } & 11.8 & $37.0 *$ & $18.5 *$ & 1.4 & -7.3 & 3.0 \\
\hline & 2.5 & $26.8 *$ & $19.8 *$ & -4.3 & 9.5 & -3.9 \\
\hline \multirow[t]{2}{*}{ i2 } & $15.8 *$ & $22.5 *$ & 24.5 & 17.2 & -1.0 & -0.1 \\
\hline & 4.3 & $23.5 *$ & 10.5 & -1.6 & 2.8 & -1.4 \\
\hline \multirow[t]{2}{*}{ i3 } & $32.3 *$ & $20.7 *$ & 11.8 & 13.5 & -10.6 & -18.0 \\
\hline & $20.2 *$ & $23.0 *$ & 15.5 & -1.6 & -3.9 & -11.4 \\
\hline \multirow[t]{2}{*}{ i4 } & $32.5 *$ & $42.8 *$ & $20.2 *$ & 10.6 & $23.5 *$ & 0.1 \\
\hline & $19.0 *$ & $33.2 *$ & $25.2 *$ & 3.9 & 6.4 & 4.0 \\
\hline \multirow[t]{2}{*}{ i5 } & $20.0 *$ & $26.0 *$ & 6.5 & 9.8 & $24.4 *$ & -2.4 \\
\hline & 15.2 & $23.7 *$ & 14.5 & 3.0 & 11.7 & -4.2 \\
\hline
\end{tabular}

B

\begin{tabular}{|c|c|c|c|c|c|}
\hline \multicolumn{6}{|l|}{ B } \\
\hline \multirow[b]{2}{*}{ Medial } & \multirow{2}{*}{$\begin{array}{l}\text { WT } \\
\text { Mid }\end{array}$} & \multirow[b]{2}{*}{ Lateral } & \multicolumn{3}{|c|}{ P2X-dblKo } \\
\hline & & & Medial & Mid & Lateral \\
\hline 0.4 & 0.6 & 0.8 & 0.2 & 1.7 & 1.3 \\
\hline 0.1 & 0.5 & 0.0 & 0.7 & 1.4 & 2.3 \\
\hline 0.5 & 2.6 & 1.9 & 1.2 & -0.5 & -3.6 \\
\hline 0.4 & 1.8 & 2.3 & -0.7 & -2.2 & -3.6 \\
\hline 3.6 & 10.4 & 4.6 & 0.0 & 2.2 & -0.5 \\
\hline 3.1 & 6.8 & 3.1 & -0.9 & -1.5 & -1.8 \\
\hline 4.0 & 8.5 & 7.1 & -1.2 & -0.8 & 0.6 \\
\hline 2.0 & 3.0 & 4.1 & -0.8 & -6.5 & -3.7 \\
\hline 4.6 & 13.4 & 2.4 & -6.3 & -5.0 & -0.3 \\
\hline 5.3 & 7.8 & 6.1 & -1.8 & -5.7 & -5.2 \\
\hline 11.6 & $19.6 *$ & 9.3 & -0.2 & -4.4 & 0.9 \\
\hline 11.6 & 16.4 & 7.9 & -5.6 & 5.0 & -1.2 \\
\hline $23.9 *$ & $25.1 *$ & 2.5 & 3.5 & -0.8 & -17.8 \\
\hline $23.0 *$ & $17.9 *$ & 6.3 & -0.5 & -4.4 & -6.8 \\
\hline $20.4 *$ & $24.4 *$ & 1.9 & $13.4 *$ & 8.1 & 5.0 \\
\hline $19.6 *$ & 17.0 & 7.1 & $10.4 *$ & 1.9 & 6.9 \\
\hline $26.1 *$ & $19.3 *$ & 4.0 & 3.8 & 9.6 & -2.4 \\
\hline 12.3 & $18.6 *$ & 4.8 & 2.7 & 3.5 & -3.5 \\
\hline
\end{tabular}

\begin{tabular}{|c|c|c|c|c|c|}
\hline \multicolumn{6}{|c|}{ D $\quad$ Glutamate- Specific } \\
\hline & \multirow{2}{*}{$\begin{array}{l}\text { WT } \\
\text { Mid }\end{array}$} & \multirow[b]{2}{*}{ Lateral } & \multicolumn{3}{|c|}{ P2X-dblKO } \\
\hline Medial & & & Medial & Mid & Latera \\
\hline 2.1 & 6.2 & 5.7 & -0.2 & -0.7 & -0.1 \\
\hline 2.2 & 6.2 & 4.8 & -0.3 & 0.5 & -0.5 \\
\hline 0.0 & 7.9 & 8.1 & 0.7 & 1.0 & 1.4 \\
\hline 1.1 & 6.0 & 7.2 & 1.7 & 2.3 & -0.2 \\
\hline 3.4 & 3.9 & 1.2 & -1.8 & -1.2 & 5.0 \\
\hline 1.1 & 2.7 & 5.9 & 1.0 & 2.9 & 4.0 \\
\hline 6.3 & $27.7 \ddagger$ & 7.1 & -1.5 & 1.1 & -0.5 \\
\hline 4.8 & 15.2 & 9.9 & -0.8 & 5.2 & -0.5 \\
\hline 7.2 & $23.6 \mp$ & 16.1 & 7.7 & -2.3 & 3.3 \\
\hline-2.8 & $19.0 \ddagger$ & 13.7 & -2.5 & 15.2 & 1.3 \\
\hline 4.2 & 2.9 & 15.2 & 17.4 & 3.4 & -1.0 \\
\hline-7.3 & 7.1 & 2.6 & 4.0 & -2.2 & -0.2 \\
\hline 8.4 & -4.4 & 9.3 & 10.0 & -9.8 & -0.2 \\
\hline-2.8 & 5.1 & 9.2 & -1.1 & 0.5 & -4.6 \\
\hline 12.1 & $18.4 \ddagger$ & 18.3 & -2.8 & 15.4 & -4.9 \\
\hline-0.6 & $16.2 \ddagger$ & 18.1 & -6.5 & 4.5 & -2.9 \\
\hline-6.1 & 6.7 & 2.5 & 6.0 & 14.8 & 0.0 \\
\hline 2.9 & 5.1 & 9.7 & 0.3 & 8.2 & -0.7 \\
\hline
\end{tabular}

Figure 6. Heat maps of the nTS show that tastant-specific activation is virtually absent in the gustatory region of the nTS of $P 2 X$-dbIKO mice. Within each chart, each three-by-two box represents one level of the nTS subdivided into the component subregions: medial-mid-lateral in dorsal (D) and ventral (V) tiers. Each heat map is color coded (blue, minimal; red, maximal) with red denoting the maximum number of c-Fos-positive cells (WT or KO) for each stimulus (water, NaCl, MSG, or glutamate) across both genotypes. $A$, The heat map for raw Fos-LI in response to water is included for comparison with the other tastant-specific heat maps. Raw c-Fos counts can be obtained by adding the water count for each subregion in $\boldsymbol{A}$ to its corresponding tastant-specific count in $\boldsymbol{B}$ and $\boldsymbol{C}$. The magenta line in $\boldsymbol{A}$ indicates the approximate boundary between gustatory/oral (anterior and lateral) and visceral (posterior and medial) representation in the nTS based on both of electrophysiological recordings of taste-evoked responses and central projections of the chorda tympani, glossopharyngeal, greater superficial petrosal nerves, the trigeminal nerve, and the vagus nerve (Whitehead and Frank, 1983; Norgren and Smith, 1988; Travers, 1993; Travers and Norgren, 1995; Hallock and Di Lorenzo, 2006; McCaughey, 2007; Whitehead and Finger, 2008; Corson et al., 2010). $\boldsymbol{A}-\boldsymbol{D}$, In WT mice, water produced little raw Fos-LI (A); however, NaCl (B), MSG (C), and glutamate (D) stimulation produce different tastant-specific (raw count for each taste minus the average water response for each subregion for each genotype) spatial patterns of activation in WT animals (left), especially within rostral (gustatory) nTS. In $P 2 X$-dbIKO mice, water produced significantly more Fos-LI (A, right) than it did in WT animals. However, tastant-specific Fos-LI in response to taste stimulation was virtually absent in rostral nTS areas in K0 mice (B-D, right). Despite the absence of tastant-induced c-Fos signal in rostral nTS in P2X-db/KO mice, significant quality-related Fos-LI remained in caudal (visceral) nTS areas. * , Significantly different from water-evoked Fos-LI within each genotype; $\neq$, MSG-evoked c-Fos expression significantly different from NaCl-evoked c-Fos expression.

tastants and water evoke similar levels and patterns of c-Fos expression. In contrast, in the gustatory nTS of WT mice, Fos-LI expression is tastant-dependent; MSG evokes the most c-Fos expression and $\mathrm{NaCl}$ induces more than water. Moreover, the pattern of c-Fos induction in the gustatory nTS in WT mice, but not $\mathrm{KO}$ mice, was quality-dependent; $\mathrm{MSG}$ and $\mathrm{NaCl}$ produced different patterns of activity. In the caudal, viscerosensory component of the nTS in both WT and KO mice, MSG and $\mathrm{NaCl}$ evoke significantly more taste-specific Fos-LI than water alone [and includes areas previously identified by Gottlieb et al. (2006) as $\mathrm{NaCl}$-responsive], suggesting that detection of nutrient-specific, postingestive cues relies on mechanisms not dependent on P2X2or P2X3-mediated transmission of information.

\section{Discussion}

Overconsumption of calorie-rich foods contributes significantly to the development of obesity. In this respect, understanding gustatory and postingestive cues for food intake is 
crucial since both types of cues influence food intake. This study reveals that postingestive cues of food quality can drive ingestive behaviors even in the absence of appetitive taste cues. Furthermore, this postingestive quality information is represented in the posterior, viscerosensory reaches of the nucleus of the solitary tract.

Animals can form a preference for a taste or flavor using only postingestive feedback signals (Sclafani, 1988; Lucas and Sclafani, 1989; de Araujo et al., 2008; Uematsu et al., 2009, 2010). This is noteworthy because although the gustatory nerves of mice that lack the $\mathrm{P} 2 \mathrm{X} 2 / \mathrm{P} 2 \mathrm{X} 3$ receptor subunits are unresponsive to all taste stimulation (Finger et al., 2005), P2X-dblKO mice do show residual behavioral responses to concentrated taste solutions (Hallock et al., 2009). These residual preferences arise from nongustatory, postingestive information, which appears largely intact in $P 2 X-d b l K O$ mice.

In fact, investigation of postingestive detection of nutrients in $P 2 X-d b l K O$ mice has the added advantage of complete elimination of gustatory neural input. This is in contrast to other KO mouse models that show partial taste impairments coupled with potential impairments of postingestive detection of nutrients. T1R3 KO mice show decreased sweet taste sensitivity (Damak et al., 2003; but see Delay et al., 2006), but still develop sucroseconditioned flavor preferences (Sclafani et al., 2010), suggesting multiple mechanisms for sweet taste exist. Additionally, although taste input is absent in $P 2 X-d b l K O$ mice, it appears that visceral function is normal. Thus, investigations of $P 2 X-d b l K O$ mice enable the determination of the interplay between taste, oral sensation, and feeding/flavor preferences without the use of surgical manipulation or direct injection of nutrient into the gut, thereby bypassing oral processing, which may be necessary for the functional breakdown of nutrients, including fats and sugars (Niijima et al., 1990; Teff, 2000; Potier et al., 2009; Stratford and Contreras, 2009).

We found that postingestive detection of glutamate is intact in $P 2 \mathrm{X}-d b l K O$ mice. Moreover, as observed in previous studies, this detection involves activation of posterior, viscerosensory parts of the nTS, rather than its anterior gustatory areas (Potier et al., 2009; Uematsu et al., 2010). We find the rostral nTS of P2XdblKO mice is equally responsive to oral stimulation by all compounds tested (water, $\mathrm{NaCl}$, and MSG), whereas these stimuli produce distinct, but partially overlapping patterns of activation in the rostral nTS of WT animals. Together, these findings suggest that postingestive feedback signals are sufficient to drive nutrient preferences and that these preferences are at least partially mediated by brainstem circuits.

Detection of nutrients in the gut involves many (Raybould, 2010) of the same receptors and downstream elements important for taste transduction within taste buds. The glutamate taste receptors T1R1, T1R3, and mGluR1 are involved in the detection of glutamate in the stomach (Hass et al., 2010; Nakamura et al., 2010). Moreover, Trpm5, a g-protein coupled cation channel necessary for the transduction of sweet, bitter, and umami (savory) taste information, is also found within duodenal enteroendocrine cells (Kokrashvili et al., 2009). Thus, taste and interoception share common receptors and mechanisms for transduction, which may be involved in their common goal of detecting nutrients-first in the oral cavity and later in the gut. Despite commonality in transduction between taste buds and the gut, transmission of this information to afferent systems is clearly different. Deletion of the P2X3 and P2X3 receptors completely blocks taste transmission via gustatory nerves but leaves interoceptive detection intact. Brain responses to glutamate require vagal nerve transmission (Uematsu et al., 2010), whereas brain activation in response to ingested glucose does not (de Araujo et al., 2008). Since $P 2 X$ - $d b l K O$ mice can respond to ingested MSG, transmission from glutamate-detecting gut receptors to the vagus nerve does not use P2X2 and P2X3 receptors that are essential for taste transmission.

\section{MSG-evoked conditioned flavor preference}

Consistent with previous studies (Colucci and Grovum, 1993; Uematsu et al., 2009, 2010), signaling evoked by postingestive detection of MSG was sufficient for mice to learn to associate ingestion of MSG with a distinct flavor (i.e., grape or cherry). More importantly, $P 2 \mathrm{X}-d b l K O$ mice developed a preference for a flavor solely by visceral detection of MSG-as P2X-dblKO animals cannot taste MSG (Finger et al., 2005). Interestingly, although both groups of mice learned to associate a flavor with the postingestive effects of MSG, $P 2 X-d b l K O$ animals consumed significantly more of the MSG-containing solution than did WT animals even during their first conditioning experience with the $\mathrm{K}^{\star}+$ MSG solution (Fig. 1A, D4). This suggests that postingestive signaling in $P 2 X-d b l K O$ mice may be more salient than in WT mice-perhaps because $P 2 X-d b l K O$ mice must rely solely on postingestive cues since the mice are unable to use gustatory information to form food preferences. Alternatively, loss of P2X receptors in the nTS, including those on primary gustatory and viscerosensory nerve terminals (Yao et al., 2001), could result in altered responsiveness of central viscerosensory nuclei.

\section{Taste quality representation in nTS}

The pattern and degree of gustatory-evoked Fos-LI in the nTS is related to taste quality. Quinine and other bitter tastants activate neurons in the medial third of the nTS, whereas sucrose activates nTS neurons situated more laterally (Harrer and Travers, 1996; King et al., 1999; Travers et al., 1999; Travers, 2002; Chan et al., 2004; Travers and Travers, 2007). In our study, MSG (and via subtraction for $\mathrm{NaCl}$-specific Fos-LI, glutamate) activates neurons in the dorsal mid region of the rostral (e.g., gustatory) portion of the nTS of WT animals. No such quality-specific activation is seen in P2Xdbl-KO animals.

Moreover, in WT mice, $\mathrm{NaCl}$ stimulation evoked approximately half the amount of Fos-LI compared with MSG with the greatest amount of $\mathrm{NaCl}$-evoked Fos-LI occurring in nTS levels caudal and lateral to those areas activated maximally by MSG (e.g., i3 and i4 vs r4 and i1). Given that visceral, nongustatory representation predominates in posterior nTS, the Fos-LI response to $\mathrm{NaCl}$ at more caudal nTS levels may reflect activation of visceral afferent systems by the $\mathrm{Na}^{+}$consumption. It should be noted however, that the ingested $\mathrm{NaCl}$ solution in our experiment was isotonic, so there should have been little osmotic load associated with consumption of this solution. Conversely, MSG activates both anterior, gustatory as well as posterior, nongustatory portions of the nTS, suggesting that the glutamate component activates both gustatory and visceral afferents.

The lack of a substantial c-Fos response to $\mathrm{NaCl}$ in rostralmost nTS points out the limitations of the c-Fos technique. $\mathrm{NaCl}$ stimulation clearly evokes electrophysiological responses in rostral parts of the nTS (Travers and Norgren, 1995; McCaughey, 2007; Kang and Lundy, 2010; Chen et al., 2011), suggesting that c-Fos expression does not entirely coincide with electrical activity. Thus, lack of c-Fos reactivity does not necessarily indicate an absence of responsiveness. On the other hand, the differential activation of c-Fos by different stimuli, and absence of c-Fos in the unstimulated condition, supports the utility of this method in 
demonstrating the location and distribution of activated neurons. The great advantage of using c-Fos as a marker of neuronal activity is that it is a noninvasive technique capable of reporting activity in awake, behaving animals. Moreover, c-Fos expression offers a means for obtaining a detailed anatomical map of activity patterns, as was the case in the current study.

\section{Quality-specific activation in $\mathrm{KO}$ mice}

Loss of taste input to the nTS though deletion of the purinergic $\mathrm{P} 2 \mathrm{X} 2 / \mathrm{P} 2 \mathrm{X} 3$ receptor subunits resulted in a corresponding loss of tastant-specific Fos-LI in anterior, gustatory parts of the nTSespecially in the dorsal tier. This correlates with the inability of these KO mice to perform quality-dependent taste behaviors. Despite the absence of quality-specific activation of gustatory nTS in P2X-dblKO mice, quality-dependent Fos-LI was evident in posterior, viscerosensory nTS. Although the relative amount of Fos-LI in the posterior nTS of $P 2 X$-dblKO mice was less than that seen in the nTS of WT mice (Fig. 5), the pattern of activation within each caudal nTS level was similar between WT and P2X$d b l K O$ mice (Fig. 6). This further indicates that interoceptive, nongustatory signaling within the nTS is still functional in P2XdblKO animals.

Together, these results provide the first evidence that postingestive signaling can drive nutrient intake in $\mathrm{P} 2 \mathrm{X}$-dblKO mice that lack taste function. In the absence of gustatory sensory information, these $\mathrm{KO}$ mice use postingestive information to develop preferences for flavors and nutrients. Further, our use of a novel method to visualize tastant-evoked central brain activation more clearly shows the chemotopic map within the nTS in WT mice. In particular, our study is the first to document MSG-specific Fos-LI in the nTS and the first to demonstrate NaCl-specific Fos-LI (e.g., the difference in $\mathrm{NaCl}$-specific c-Fos expression between WT and $P 2 X-d b l K O$ mice) in anterior, gustatory nTS. The addition of these patterns of Fos-LI will contribute significantly to future nTS coding models and also illustrate the necessity of thorough characterization of tastant-specific activity within the nTS.

\section{References}

Archer S, Li TT, Evans AT, Britland ST, Morgan H (1999) Cell reactions to dielectrophoretic manipulation. Biochem Biophys Res Commun 257:687-698.

Berthoud HR (2002) Multiple neural systems controlling food intake and body weight. Neurosci Biobehav Rev 26:393-428.

Chan CY, Yoo JE, Travers SP (2004) Diverse bitter stimuli elicit highly similar patterns of Fos-like immunoreactivity in the nucleus of the solitary tract. Chem Senses 29:573-581.

Chen JY, Victor JD, Di Lorenzo PM (2011) Temporal coding of intensity of $\mathrm{NaCl}$ and $\mathrm{HCl}$ in the nucleus of the solitary tract of the rat. J Neurophysiol 105:697-711.

Clark EC, Dodge HW Jr (1955) Extraolfactory components of flavor. J Am Med Assoc 159:1721-1723.

Colucci PE, Grovum WL (1993) Factors affecting the voluntary intake of food by sheep. 6 . The effect of monosodium glutamate on the palatability of straw diets by sham-fed and normal animals. Br J Nutr 69:37-47.

Corson JA, Erisir A, Hill D (2010) Receptive field mapping of the oral cavity in the rostral nucleus of the solitary tract. Chem Senses (Abstr) 35:630.

Damak S, Rong M, Yasumatsu K, Kokrashvili Z, Varadarajan V, Zou S, Jiang P, Ninomiya Y, Margolskee RF (2003) Detection of sweet and umami taste in the absence of taste receptor T1r3. Science 301:850-853.

de Araujo IE, Oliveira-Maia AJ, Sotnikova TD, Gainetdinov RR, Caron MG, Nicolelis MA, Simon SA (2008) Food reward in the absence of taste receptor signaling. Neuron 57:930-941.

Delay ER, Hernandez NP, Bromley K, Margolskee RF (2006) Sucrose and monosodium glutamate taste thresholds and discrimination ability of T1R3 knockout mice. Chem Senses 31:351-357.

Eddy MC, Eschle BK, Barrows J, Hallock RM, Finger TE, Delay ER (2009)
Double $\mathrm{P} 2 \mathrm{X} 2 / \mathrm{P} 2 \mathrm{X} 3$ purinergic receptor knockout mice do not taste $\mathrm{NaCl}$ or the artificial sweetener SC45647. Chem Senses 34:789-797.

Finger TE, Danilova V, Barrows J, Bartel DL, Vigers AJ, Stone L, Hellekant G, Kinnamon SC (2005) ATP signaling is crucial for communication from taste buds to gustatory nerves. Science 310:1495-1499.

Glendinning JI, Yiin YM, Ackroff K, Sclafani A (2008) Intragastric infusion of denatonium conditions flavor aversions and delays gastric emptying in rodents. Physiol Behav 93:757-765.

Gottlieb HB, Ji LL, Jones H, Penny ML, Fleming T, Cunningham JT (2006) Differential effects of water and saline intake on water deprivationinduced c-Fos staining in the rat. Am J Physiol Regul Integr Comp Physiol 290:R1251-R1261.

Guthrie KM, Anderson AJ, Leon M, Gall C (1993) Odor-induced increases in c-fos mRNA expression reveal an anatomical "unit" for odor processing in olfactory bulb. Proc Natl Acad Sci U S A 90:3329-3333.

Hallock RM, Di Lorenzo PM (2006) Effects of electrical stimulation of the glossopharyngeal nerve on cells in the nucleus of the solitary tract of the rat. Brain Res 1113:163-173.

Hallock RM, Tatangelo M, Barrows J, Finger TE (2009) Residual chemosensory capabilities in double $\mathrm{P} 2 \mathrm{X} 2 / \mathrm{P} 2 \mathrm{X} 3$ purinergic receptor null mice: intraoral or postingestive detection? Chem Senses 34:799-808.

Harrer MI, Travers SP (1996) Topographic organization of Fos-like immunoreactivity in the rostral nucleus of the solitary tract evoked by gustatory stimulation with sucrose and quinine. Brain Res 711:125-137.

Hass N, Schwarzenbacher K, Breer H (2010) T1R3 is expressed in brush cells and ghrelin-producing cells of murine stomach. Cell Tissue Res 339:493-504.

Kang Y, Lundy RF (2010) Amygdalofugal influence on processing of taste information in the nucleus of the solitary tract of the rat. J Neurophysiol 104:726-741.

King CT, Travers SP, Rowland NE, Garcea M, Spector AC (1999) Glossopharyngeal nerve transection eliminates quinine-stimulated fos-like immunoreactivity in the nucleus of the solitary tract: implications for a functional topography of gustatory nerve input in rats. J Neurosci 19:3107-3121.

Kokrashvili Z, Rodriguez D, Yevshayeva V, Zhou H, Margolskee RF, Mosinger B (2009) Release of endogenous opioids from duodenal enteroendocrine cells requires Trpm5. Gastroenterology 137:598-606, 606.e1-2.

Kulkosky PJ, Gray L, Gibbs J, Smith GP (1981) Feeding and selection of saccharin after injections of bombesin, $\mathrm{LiCl}$, and $\mathrm{NaCl}$. Peptides 2:61-64.

Lucas F, Sclafani A (1989) Flavor preferences conditioned by intragastric fat infusions in rats. Physiol Behav 46:403-412.

McCaughey SA (2007) Taste-evoked responses to sweeteners in the nucleus of the solitary tract differ between C57BL/6ByJ and 129P3/J mice. J Neurosci 27:35-45.

Nakamura E, Hasumura M, San Gabriel A, Uneyama H, Torii K (2010) New frontiers in gut nutrient sensor research: luminal glutamate-sensing cells in rat gastric mucosa. J Pharmacol Sci 112:13-18.

Niijima A, Togiyama T, Adachi A (1990) Cephalic-phase insulin release induced by taste stimulus of monosodium glutamate (umami taste). Physiol Behav 48:905-908.

Norgren R, Smith GP (1988) Central distribution of subdiaphragmatic vagal branches in the rat. J Comp Neurol 273:207-223.

Paxinos G, Franklin KB (2001) The mouse brain in stereotaxic coordinates, 2nd edition. San Diego: Academic.

Potier M, Darcel N, Tomé D (2009) Protein, amino acids and the control of food intake. Curr Opin Clin Nutr Metab Care 12:54-58.

Raybould HE (2010) Gut chemosensing: interactions between gut endocrine cells and visceral afferents. Auton Neurosci 153:41-46.

Schwarz J, Burguet J, Rampin O, Fromentin G, Andrey P, Tomé D, Maurin Y, Darcel N (2010) Three-dimensional macronutrient-associated Fos expression patterns in the mouse brainstem. PLoS One 5:e8974.

Sclafani A (1988) Carbohydrate appetite in rats: taste and postingestive factors. Appetite 11 [Suppl 1]:20-25.

Sclafani A, Glass DS, Margolskee RF, Glendinning JI (2010) Gut T1R3 sweet taste receptors do not mediate sucrose-conditioned flavor preferences in mice. Am J Physiol Regul Integr Comp Physiol 299:R1643-R1650.

Stratford JM, Contreras RJ (2009) Saliva and other taste stimuli are important for gustatory processing of linoleic acid. Am J Physiol Regul Integr Comp Physiol 297:R1162-R1170.

Teff K (2000) Nutritional implications of the cephalic-phase reflexes: endocrine responses. Appetite 34:206-213. 
Travers JB, Urbanek K, Grill HJ (1999) Fos-like immunoreactivity in the brain stem following oral quinine stimulation in decerebrate rats. Am J Physiol 277:R384-R394.

Travers SP (1993) Orosensory Processing in neural systems of the nucleus of the solitary tract. In: Mechanisms of taste transduction (Simon SA, Roper SD, eds), pp 339-383. Boca Raton, Florida: CRC.

Travers SP (2002) Quinine and citric acid elicit distinctive Fos-like immunoreactivity in the rat nucleus of the solitary tract. Am J Physiol Regul Integr Comp Physiol 282:R1798-R1810.

Travers SP, Norgren R (1995) Organization of orosensory responses in the nucleus of the solitary tract of rat. J Neurophysiol 73:2144-2162.

Travers SP, Travers JB (2007) Taste-evoked Fos expression in nitrergic neurons in the nucleus of the solitary tract and reticular formation of the rat. J Comp Neurol 500:746-760.

Uematsu A, Tsurugizawa T, Kondoh T, Torii K (2009) Conditioned flavor preference learning by intragastric administration of L-glutamate in rats. Neurosci Lett 451:190-193.
Uematsu A, Tsurugizawa T, Uneyama H, Torii K (2010) Brain-gut communication via vagus nerve modulates conditioned flavor preference. Eur J Neurosci 31:1136-1143.

Watson RE Jr, Wiegand SJ, Clough RW, Hoffman GE (1986) Use of cryoprotectant to maintain long-term peptide immunoreactivity and tissue morphology. Peptides 7:155-159.

Whitehead MC, Finger TE (2008) Gustatory pathways in fish and mammals. In: The senses: a comprehensive reference, 1 st edition (Basbaum AI, ed), pp 237-260. Amsterdam: Elsevier.

Whitehead MC, Frank ME (1983) Anatomy of the gustatory system in the hamster: central projections of the chorda tympani and the lingual nerve. J Comp Neurol 220:378-395.

Yao ST, Barden JA, Lawrence AJ (2001) On the immunohistochemical distribution of ionotropic $\mathrm{P} 2 \mathrm{X}$ receptors in the nucleus tractus solitarius of the rat. Neuroscience 108:673-685.

Zheng H, Berthoud HR (2008) Neural systems controlling the drive to eat: mind versus metabolism. Physiology (Bethesda) 23:75-83. 